\title{
The Effects of $\beta$-Galactosidase Activity and Cyclic AMP on Lactose-accelerated Death
}

\author{
By P. H. CALCOTT \\ Department of Microbiology, MacDonald College of McGill University, \\ Montreal, P.Q., Canada \\ AND J. R. POSTGATE \\ A.R.C. Unit of Nitrogen Fixation, University of Sussex, Brighton, BNI $9 Q J$
}

(Received 30 May 1974)

SUMMARY

\begin{abstract}
Lactose-limited chemostat populations of Klebsiella aerogenes 418 showed hyper- $\beta$-galactosidase activity after 170 generations. Within the normally active phase, hyperactivity could be induced by adding thiomethyl- $\beta$-D-galactoside and was lost on its removal; natural hyper-activity was lost on transfer to a lactose medium in which ammonium was limiting. The ability of lactose to accelerate death from starvation was proportional to the $\beta$-galactosidase activity of the population. Cyclic AMP in the recovery medium alleviated lactose-accelerated death. Suppression of adenyl cyclase activity by traumatic substrates may be responsible for substrate-accelerated death.
\end{abstract}

\section{INTRODUCTION}

While much information is available concerning the circumstances of substrate-accelerated death, the precise mechanism is not fully understood. For expression of the phenomenon with Klebsiella aerogenes, the organism must be grown on the carbon source, subsequently starved in its presence and finally transferred to a recovery medium containing that substrate (Calcott \& Postgate, I97I, I972). Starvation in the presence of the traumatic agent does not, in itself, kill the organisms but only predisposes it to non-division on the recovery medium. It now seems likely that the phenomenon involves acute repression of the organism, in the starvation environment, by the traumatic agent, with the associated loss of the nucleotide, $3^{\prime}-5^{\prime}$ cyclic adenosine monophosphate (cAMP), resulting in the non-division of the organisms on certain recovery media (Calcott, Montague \& Postgate, 1972). This view prompted two further questions: Do organisms at different levels of induction succumb to the stress at different rates? Do the organisms actually die on the recovery medium?

\section{METHODS}

Klebsiella aerogenes (NCIB4I8) was cultivated at $37^{\circ} \mathrm{C}$ aerobically in a chemostat under lactose or glycerol limitation as described by Calcott \& Postgate (1972) or ammonium limitation using the medium described by Postgate \& Hunter (I962) with lactose as sole carbon source $(\mathrm{I} \circ \mathrm{g} / \mathrm{l})$ and $\mathrm{NH}_{4} \mathrm{Cl}(6 \mathrm{~mm})$. Culture samples were harvested, washed and starved at 20 or $100 \mu \mathrm{g}$ dry wt bacteria/ml as described previously (Calcott et al. 1972). Viability was determined by slide culture (Postgate, Crumpton \& Hunter, I96I) using the lactose recovery medium of Calcott \& Postgate (1972). 


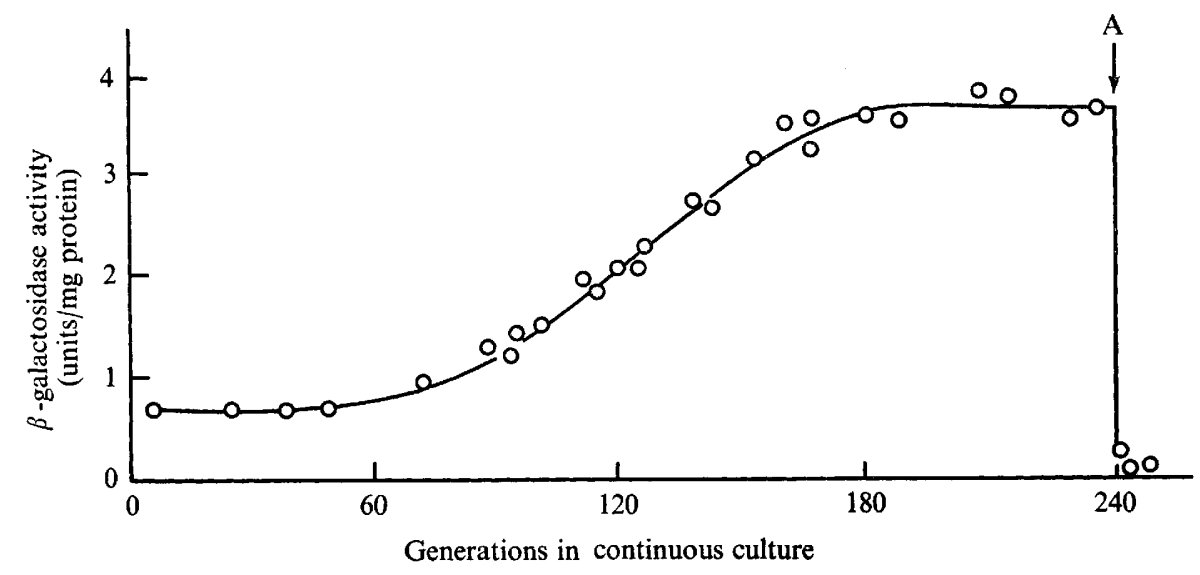

Fig. 1. $\beta$-Galactosidase activity of Klebsiella aerogenes in chemostat culture. An inoculum of Klebsiella aerogenes from a lactose-limited batch culture was grown continuously, $D=0.23 \mathrm{~h}^{-1}$ at $37{ }^{\circ} \mathrm{C}$ aerobically. $\beta$-Galactosidase activity was determined on toluenized preparations (see Methods) once steady state had been attained. Initially, the culture was lactose-limited ( $2 \mathrm{~g} / \mathrm{l})$ but after 240 generations the medium was changed to a glycerol-limiting one $(2 \mathrm{~g} / 1)$ at $\mathrm{A}$.

Protein was assayed as previously described (Calcott \& Postgate, 1972). $\beta$-Galactosidase activity was assayed as $o$-nitrophenyl $\beta$-D-galactoside hydrolysis by toluene-treated bacteria (Strange, I96I), one unit of $\beta$-galactosidase being taken as that needed to produce $\mathrm{I} \mu \mathrm{mol}$ $o$-nitrophenol $/ \mathrm{min}$ at $25^{\circ} \mathrm{C}$.

Chemicals were of analytical grade where available.

\section{RESULTS}

\section{$\beta$-Galactosidase activity in continuous culture populations}

The $\beta$-galactosidase activity of culture samples was determined at intervals after steady state conditions had been attained in the chemostat (as judged by opacity measurements). Over the first 39 generations the activity was constant at 0.47 units $/ \mathrm{mg}$ protein. However, after 240 generations 'hyper-levels' were observed similar to those reported by Horiuchi, Tomizawa \& Novick (I962), Novick \& Horiuchi (1962) and Smith \& Dean (1972). An increase to 3.5 units $/ \mathrm{mg}$ protein took place, though not as suddenly as reported by these workers; it started at about the 70 th generation and was complete about 170 generations after the onset of steady state (Fig. I). Even after 240 generations the population was not constitutive for $\beta$-galactosidase since, on changing the input medium to a glycerol-limiting one, $\beta$-galactosidase activity decreased to the limits of detection. A similar increase in activity was studied with a lower population density limited by a lactose concentration of $0.5 \mathrm{~g} / \mathrm{l}$ (Fig. 2). In these experiments, rate of induction of these 'hyper-levels' of enzyme was increased by including, with lactose, the inducer of the lac-operon thiomethyl- $\beta$-Dgalactoside (TMG) at I.5 mM; 'hyper-levels' were then produced in four generations. Transfer back to the unsupplemented lactose medium resulted in equally rapid loss of the 'hyper-levels' to the value before the inducer was added. Once hyper-levels of the enzyme were produced without inducer, a change to ammonium-limiting conditions while retaining lactose as sole carbon source resulted in a decrease of activity to I unit/mg protein. 


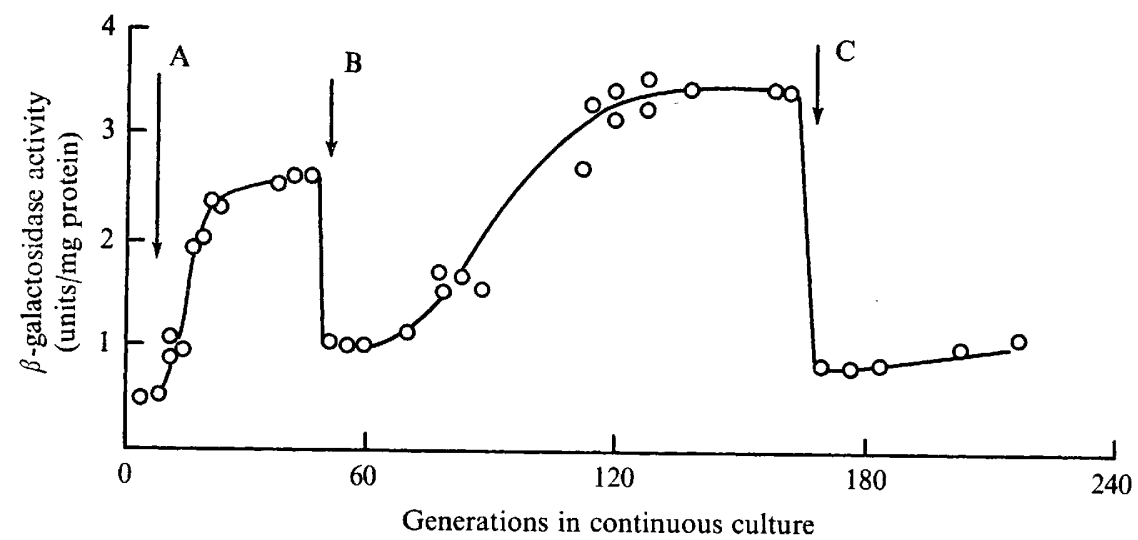

Fig. 2. $\beta$-Galactosidase activity of Klebsiella aerogenes in chemostat culture. A chemostat was set up as for Fig. I except that the inoculum was taken from the chemostat in Fig. I after 70 generations and the inflow medium contained $0.5 \mathrm{~g}$ lactose $/ 1$ initially. The medium was altered at $\mathrm{A}$ to retaining limiting lactose but with a gratuitous inducer $(0.5 \mathrm{~g}$ lactose $/ 1+\mathrm{I} \cdot 5 \mathrm{mM}-\mathrm{TMG})$. At $\mathrm{B}$, normal lactose-limiting conditions $(0.5 \mathrm{~g} / 1)$ were restored; at $\mathrm{C}$, the medium was again altered to produce lactose-utilizing, ammonium-limiting conditions ( $\mathrm{o}$ g lactose $/ 1+6 \mathrm{~mm}-\mathrm{NH}_{4} \mathrm{Cl}$ ). $\beta$-Galactosidase activity was determined as described in Methods.

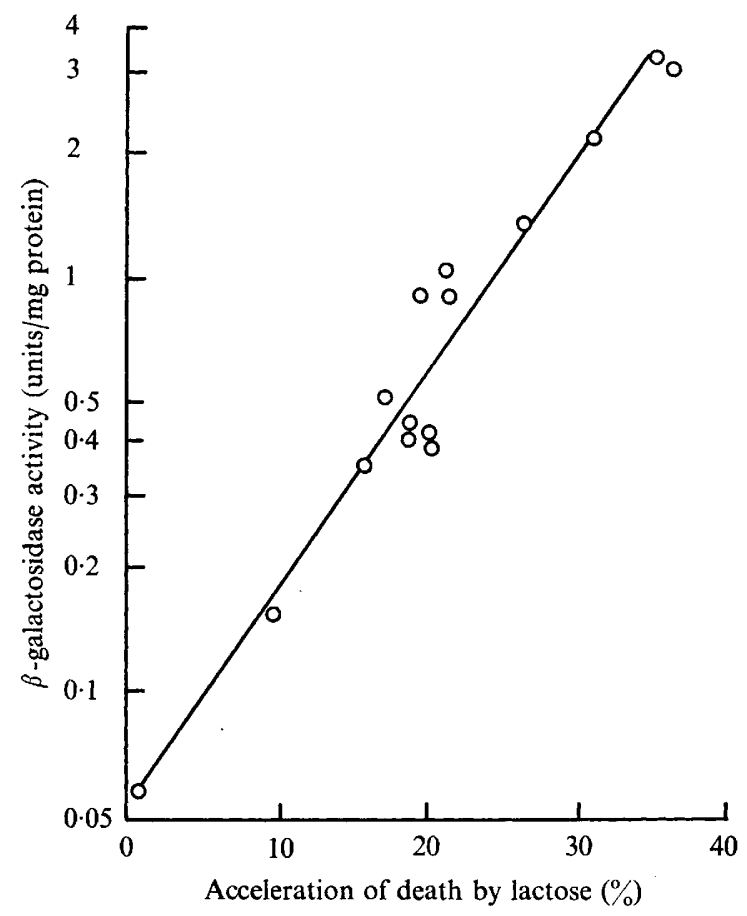

Fig. 3. Correlation between $\beta$-galactosidase activity and ability of lactose to accelerate the death of populations of Klebsiella aerogenes. The $\beta$-galactosidase activities and the accelerated death rate by $5 \mathrm{~mm}$-lactose of various chemostat populations of $K$. aerogenes starving at $100 \mu \mathrm{g} \mathrm{dry} \mathrm{wt} / \mathrm{ml}$ saline phosphate at $37^{\circ} \mathrm{C}$ were determined. 


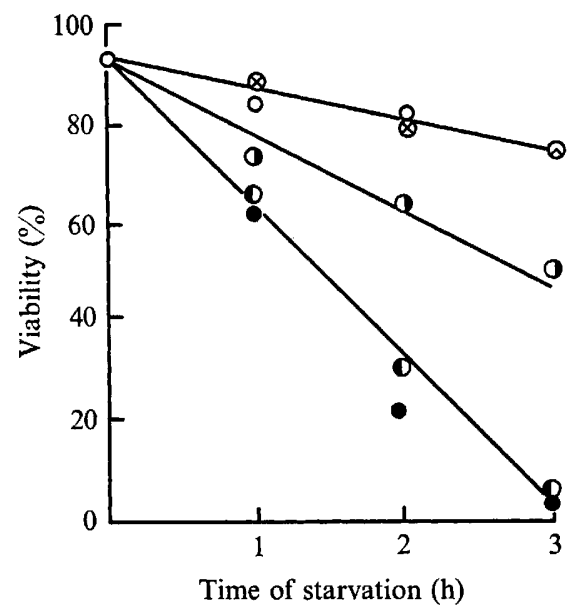

Fig. 4. Effect of cAMP in the recovery medium on lactose-accelerated death of Klebsiella aerogenes. Washed, lactose-limited $K$. aerogenes were starved at $20 \mu \mathrm{g}$ dry $\mathrm{wt} / \mathrm{ml}$ saline phosphate with or without $5 \mathrm{~mm}$-lactose at $37^{\circ} \mathrm{C}$. Viabilities were determined by slide culture on a lactose-based recovery medium with or without cAMP: starved without lactose $(O)$; starved with lactose, recovered on unsupplemented lactose medium (๑); starved with lactose, recovered on lactose medium with (O) I mM-, ( 3 mM- or $(\otimes) 5$ mM-cyclic AMP.

\section{Level of $\beta$-galactosidase and lactose-accelerated death rates}

Fig. 3 shows the linear death rates in the presence of lactose of populations of different specific $\beta$-galactosidase activities tested during these experiments. Populations whose lacoperon was not derepressed possessed minimal levels of $\beta$-galactosidase and showed low levels of lactose-accelerated death; those with intermediate levels of the enzyme (such as lactose-grown, ammonium-limited populations) showed intermediate acceleration of death, while those with 'hyper-levels' showed pronounced acceleration of death by lactose.

\section{Effect of cAMP in the recovery medium}

The death rates of populations starved in saline phosphate with and without lactose ( $5 \mathrm{mM}$ ) were determined on the lactose recovery medium with and without CAMP at various levels. In a typical experiment, when the organisms were starved in buffer alone the death rates were identical, whether viabilities were determined on the recovery media with or without cAMP (up to $5 \mathrm{mM}$ ) (Fig. 4). However, when the organism was starved in the presence of lactose, the death rates depended on the level of cAMP in the recovery medium. At I mM cAMP had no effect, but at $3 \mathrm{mM}$ cAMP alleviated lactose-accelerated death partially and at $5 \mathrm{~mm}$ it did so completely.

\section{DISCUSSION}

With strains of bacteria which produce hyper-levels of $\beta$-galactosidase activity, the enzyme produced is normal in $K_{m}$, specific activity, sedimentation pattern, immunological properties and thermal stability (Horiuchi et al. 1962; Novick \& Horiuchi, 1962). Hence, the hyperactive strains produce more enzyme and not one of higher specific activity. The former authors reported that the ability to produce hyper-levels of the enzyme could be transferred genetically to other strains and could be a gene dosage effect, reflecting extra copies of the 
lac-operon. Smith \& Dean (1972) doubt this, attributing hyper-activity to improved gene expression. Our experiments support the view of Smith \& Dean (1972) in that the ready loss of the hyper-active state in conditions in which more prolonged selection restores it (Fig. 2) is not consistent with selection at the genetic level.

The level of the enzyme is a measure of induction or derepression of the lac-operon (i.e. the rate of initiation of transcription), because messenger half-life and rate of chain-elongation of transcription and translation are apparently constant over a wide range of growth conditions (Coffman, Norris \& Koch, 197I). Thus, the susceptibility of a lactose-limited population to lactose during starvation can be correlated to the level of induction/derepression of the lac-operon: those populations which were highly induced were more susceptible than those which were induced to a lower level. These findings are compatible with those of Strange \& Dark (1965) who showed that glycerol-grown populations which utilized glycerol fastest, died fastest when starved in the presence of that substrate.

The finding that $5 \mathrm{~mm}$-cAMP in the lactose recovery medium completely alleviated lactoseaccelerated death indicates that the organisms need not necessarily die when transferred to a recovery medium containing lactose. In this respect, organisms starved in the presence of lactose appear to be behaving like the adenyl cyclase mutants of Pastan \& Perlman (1970). These mutants, which contained undetectable levels of cAMP and had low levels of cyclase activity, did not grow on carbon sources such as lactose or arabinose whose metabolism required induction, and grew only slowly on carbon sources such as glucose whose metabolism was constitutive. Addition of cAMP to the medium permitted normal growth on all the carbon sources.

Organisms suffering from lactose-accelerated death contain low levels of cAMP (Calcott et al. 1972), but it is uncertain how the level of the nucleotide is depressed. Three possible factors can govern the level of the nucleotide in the bacterium: the level of adenyl cyclase, which forms cAMP from ATP; the level of phosphodiesterase, which breaks it down to 5'-AMP; or release of cAMP into the medium (Pastan \& Perlman, 1970). Calcott et al. (1972) presented evidence that turnover of the nucleotide was occurring, since theophylline (an inhibitor of phosphodiesterase) altered the level of the nucleotide in the organism, and that large quantities of the nucleotide were released into the medium.

Strange (1967) mentioned that high levels of the substrate for adenyl cyclase, ATP, are available in the bacterium during substrate-accelerated death, an observation which we have confirmed in unpublished experiments. For reasons of economy, one would envisage immediate control of cAMP concentration occurring at the phosphodiesterase and/or release level and longer-term control at the cyclase level. Since the level of induction of the lac-operon seems to govern the observed rate of lactose-accelerated death, it is possible that the traumatic substrate might depress adenyl cyclase synthesis or function through a more central control mechanism linked to the apparatus regulating use of that substrate: the lac-operon in the case of lactose.

\section{REFERENCES}

Calcott, P. H., Montague, W. \& Postgate, J. R. (1972). The levels of cyclic AMP during substrateaccelerated death. Journal of General Microbiology 73, 197-200.

Calcott, P. H. \& Postgate, J. R. (I97I). Substrate-accelerated death: role of recovery medium and prevention by cyclic AMP. Journal of General Microbiology 66, i.

Calcott, P. H. \& Postgate, J. R. (I972). On substrate-accelerated death in Klebsiella aerogenes. Journal of General Microbiology 70, $115-122$.

Coffman, R. L., Norris, T. E. \& Koch, A. L. (1971). Chain elongation rate of messenger and polypeptides in slowly growing Escherichia coli. Journal of Molecular Biology 6o, I-19. 
Horiuchi, T., Tomizawa, T. \& Novick, A. (I962). Isolation and properties of bacteria capable of high rates of $\beta$-galactosidase. Biochimica et biophysica acta 55, I52-163.

Novick, A. \& HoRIUCHI, T. (1962). Hyper-production of $\beta$-galactosidase by Escherichia coli bacteria. Cold Spring Harbor Symposia on Quantitative Biology 26, 239-245.

Pastan, I. \& Perlman, R. (1970). Cyclic adenosine monophosphate in bacteria. Science, New York I69, 339-344.

Postgate, J. R., Crumpton, J. E. \& Hunter, J. R. (196I). The measurement of bacterial viability by slide culture. Journal of General Microbiology 24, I5-24.

Postgate, J. R. \& HUnTER, J. R. (1962). The survival of starved bacteria. Journal of General Microbiology 29, $233-263$.

Smith, R. W. \& Dean, A. C. R. (1972). $\beta$-Galactosidase synthesis in Klebsiella aerogenes growing in continous culture. Journal of General Microbiology 72, 37-47.

STRANGE, R. E. (196I). Induced enzyme synthesis in aqueous suspensions of starved stationary phase Aerobacter aerogenes. Nature, London I9r, I272-1 273.

Strange, R. E. (1967). In Microbial Physiology and Continuous Culture, Proceedings of the 3 rd International Symposium, p. I22. Edited by E. O. Powell, C. G. T. Evans, R. E. Strange and D. W. Tempest. London: Her Majesty's Stationery Office.

Strange, R. E. \& DARK, F. A. (1965). Substrate-accelerated death of Aerobacter aerogenes. Journal of General Microbiology 39, 21 5-228. 